\title{
Physical Properties of Thermal Plumes from a Nuclear Power Plant in the Southernmost Taiwan
}

\author{
Sen Jan \\ Institute of Hydrological Sciences, National Central University, 300 Jungda Road, Jung-li, Taiwan 32001, R.O.C., \\ senjan@cc.ncu.edu.tw \\ Chen-Tung Arthur Chen \\ Institute of Marine Geology and Chemistry, National Sun Yat-Sen University, 70 Lien-hai Road, Kaohsiung, Taiwan \\ 80424, R.O.C. \\ Yueh-Yuan Tu \\ Department of Industrial Safety and Environmental Protection, Taiwan Power Company, Taipei, Taiwan 10016, R.O.C. \\ Hsien-Shiow Tsai \\ Department of Industrial Safety and Environmental Protection, Taiwan Power Company, Taipei, Taiwan 10016, R.O.C.
}

Follow this and additional works at: https://jmstt.ntou.edu.tw/journal

Part of the Terrestrial and Aquatic Ecology Commons

\section{Recommended Citation}

Jan, Sen; Chen, Chen-Tung Arthur; Tu, Yueh-Yuan; and Tsai, Hsien-Shiow (2004) "Physical Properties of Thermal Plumes from a Nuclear Power Plant in the Southernmost Taiwan," Journal of Marine Science and Technology. Vol. 12: Iss. 5 , Article 10. DOI: $10.51400 / 2709-6998.2265$

Available at: https://jmstt.ntou.edu.tw/journal/vol12/iss5/10

This Research Article is brought to you for free and open access by Journal of Marine Science and Technology. It has been accepted for inclusion in Journal of Marine Science and Technology by an authorized editor of Journal of Marine Science and Technology. 


\section{Physical Properties of Thermal Plumes from a Nuclear Power Plant in the Southernmost Taiwan}

\section{Acknowledgements}

The Taiwan Power Company funded the project. Ms. B.-J. Wang kindly provided nutrient data. Mr. J.-T. Wen and Mr. F.-H. Huang assisted field work. Comments from two anonymous reviewers and invaluable suggestions from Prof. Shenn-Yu Chao of the University of Maryland Center for Environment Science (UMCES) improved the presentation of the paper. 


\title{
PHYSICAL PROPERTIES OF THERMAL PLUMES FROM A NUCLEAR POWER PLANT IN THE SOUTHERNMOST TAIWAN
}

\author{
Sen Jan*, Chen-Tung Arthur Chen**, Yueh-Yuan Tu***, and Hsien-Shiow Tsai***
}

Key words: nuclear power plant, thermal plume, tidal current.

\begin{abstract}
Circulation and hydrographic variations in the inner shelf of a semi-enclosed bay adjacent to a nuclear power plant of the southernmost Taiwan were analyzed using intensive observation data from 2003-2004. The dominant tide in the bay is a mixture of diurnal and semidiurnal components. Currents are dominated by tidal forcing which flows southwestward during flood and northeastward during ebb. The amplitudes of tidal currents range from 0.2 to $0.4 \mathrm{~m} / \mathrm{s}$. A persistent southwestward subtidal flow is present with a mean velocity of $0.15 \mathrm{~m} / \mathrm{s}$. The upwelled cold deep water in the central bay can intrude to the inner reach near the outlet, causing sudden temperature drops. Thermal discharge from the power plant creates a buoyant plume near the sea surface, which is the most prominent feature in the receiving water around the outlet. The thermal plume is 5-7 m thick just outside the outlet and shoals to less than $1 \mathrm{~m}$ near the sea surface as it disperses seaward. The thermal plume is usually restricted to within a $1000 \mathrm{~m}$ radius around the outlet; tidal currents substantially modulated its shape, stretching it out as a tongue towards the southwest during flood but fanning it out towards the northeast during ebb. The thermal discharge does not recirculate back to the intake.
\end{abstract}

\section{INTRODUCTION}

Heated cooling water released from nuclear power stations at coastal regions raises significant concerns about the conservation of the marine environments. The heated water is typically pumped into the coastal water through an open channel, possibly forming a thermal plume and causing modulations of coastal circulation through the baroclinic effect. The discharge might be a thermal pollutant endangering the ecosystem. Monitoring the thermal effluents and the associated hydrographic variations in the coastal water close to a nuclear

Paper Submitted 10/12/04, Accepted 01/21/05. Author for Correspondence: Sen Jan.E-mail:senjan@cc.ncu.edu.tw.

*Institute of Hydrological Sciences, National Central University, 300 Jungda Road, Jung-li, Taiwan 32001, R.O.C.

**Institute of Marine Geology and Chemistry, National Sun Yat-Sen University, 70 Lien-hai Road, Kaohsiung, Taiwan 80424, R.O.C.

***Department of Industrial Safety and Environmental Protection, Taiwan Power Company, Taipei, Taiwan 10016, R.O.C. power plant is therefore crucial to understanding the marine environment and assessing their effect on the ecosystem.

The third nuclear power plant of the Taiwan Power Company (hereafter referred to as Taipower) was constructed at the southernmost coast of Taiwan (Fig. 1) and began operating in 1984. Located at the west coast of the semi-enclosed Nan Wan Bay, the power plant pumps in coastal water to cool the generators and releases the heated water back to the surrounding sea. The bay is open southward to the Luzon Strait which links the South China Sea and the western Pacific Ocean. The exchange of the Kuroshio water, South China Sea water and local coastal water causes a complex seasonal variation of water masses in the bay (Chen et al., 1994). The swift tidal currents together with intermittent internal waves cause upwelling of cold bottom water in the central bay that might intrude towards the shallow inner shelf causing sudden temperature drops (Chen et al., 1994; Lee et al., 1997; Lien et al., 2004). To evaluate the effect of human activity on the marine environment, Taipower commissioned research institutes and universities, including Taiwan's Acdemia Sinica, Na-

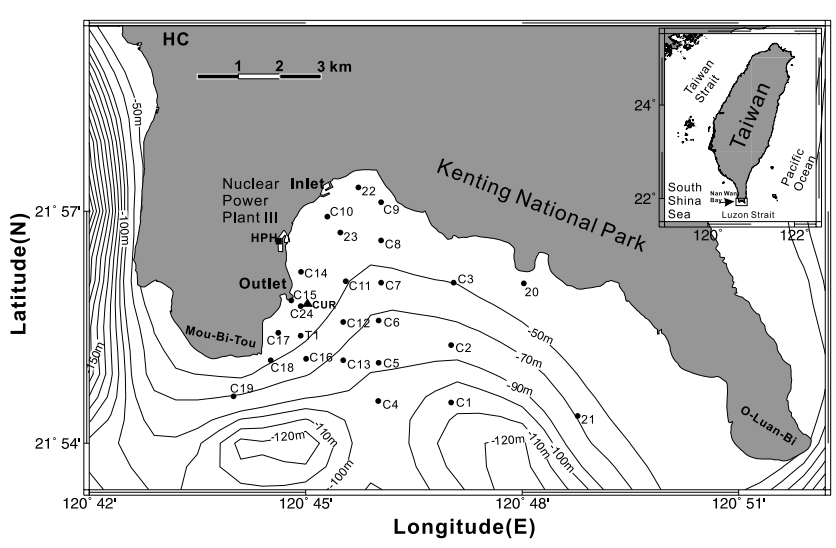

Fig. 1. Bathymetric chart of the Nan Wan Bay. The CTD stations are indicated by full-circles, current meter station CUR by a fulltriangle and tide-gauge station HPH by a square. The wind station is indicated by HC. 
tional Taiwan University and National Sun Yat-Sen University, to monitor the variations in circulation, hydrography, water quality, ecology and fishery economy in the receiving waters of the power plant. This work focuses only on analyzing the properties of physical hydrography, including tides, currents and temperature variations.

Early investigations (e.g., Liang et al., 1978; Su et al., 1984, 1989, 1991; Fan, 1988; Chen et al., 2003) confirmed that tidal currents off the outlet generally flow along the coast, southwestward during flood and northeastward during ebb. The amplitudes of tidal currents range from 0.03 to $0.3 \mathrm{~m} / \mathrm{s}$ near the outlet. The subtidal flow is southwestward with a velocity in the range $0.1-0.2 \mathrm{~m} / \mathrm{s}$. Tides in the coastal region are predominantly diurnal. The diurnal tides frequently mask the semidiurnal tides, leading to spring and neap tides that are unrelated to semidiurnal tides. Spring and neap tides in the bay are therefore defined respectively by periods of high and low tidal ranges in a fortnightly cycle (Lee et al., 1997). The mean tidal range is $1.8 \mathrm{~m}$ during spring tide and $0.5 \mathrm{~m}$ during neap tide. Carried by surface currents, drifter released at the outlet drifts southwestward hugging the Mou-Bi-Tou coast during flood and predominantly towards east to northeast during ebb. Yu et al. (1998, 1999, 2000), from the Tainan Hydraulics Laboratory, monitored the thermal effluents and concluded that the warmer and lighter discharge forms a thermal plume floating over the surface layer (depth $<3 \mathrm{~m}$ ) after departing from the outlet. The shape of the thermal plume is controlled by tidal streams, extending southward during flood but dispersing to the east during ebb. The thermal plume is generally restricted to a $1000 \mathrm{~m}$ radius around the outlet. The sea surface temperature (at $1 \mathrm{~m}$ depth) decreases by about 4 $8^{\circ} \mathrm{C}$ from the outlet to the perimeter of the thermal plume. Su et al. (1991) concluded that the thermal discharge does not affect the intake of cooling water.

These historical observations provide information about essential hydrographic features for the coastal waters adjacent to the power plant to lowest order. From 2003, researchers have carried out intensive investigations to improve our understanding of the thermal effluents and the background environment. The objective of this study is to analyze the observational results, especially those related to thermal plumes. Observational results will hopefully lead to future numerical model development.

\section{OBSERVATIONS}

Currents at the location of $120^{\circ} 45.042^{\prime} \mathrm{E}$ and $21^{\circ} 55$. $821^{\prime} \mathrm{N}$ (station CUR in Fig. 1) were measured with a Nortek Aquadopp acoustic Doppler current meter. The mooring site was about $200 \mathrm{~m}$ southeast of the outlet, where the water depth is $28 \mathrm{~m}$. The current meter was installed at $6 \mathrm{~m}$ below sea surface and measured current speed and direction continuously. The hourly velocity data were analyzed using traditional statistics, the Fourier transform and the harmonic analysis (Foreman, 1977). The Morlet wavelet transform (Morlet, 1983; Emery and Thomson, 1998) was adopted for localizing and quantifying the variability of currents simultaneously in both frequency and time domains. Relevant sea level fluctuations at a tide-gauge station midway between the inlet and the outlet (HPH in Fig. 1) and winds at a weather station north of the power plant (HC in Fig. 1) were collected from the Taiwan Central Weather Bureau.

Hydrographic variations were measured with a Sea Bird SBE-19 portable CTD (Conductivity-Temperature-Depth sensors). Each survey consisted of 25 casts (full circles in Fig. 1) within four hours during a tidal phase. Since a four-hour duration is not a negligible fraction of a tidal period, the hydrographic distributions derived from the CTD observations are only quasi-synoptic. By comparison, the spatial variation of salinity is smaller than that of temperature during a survey period and therefore this study only presents temperature variations. To better resolve the thermal plume, intensive CTD surveys of 43 stations in a fanshaped area of $1,000 \mathrm{~m}$ radius around the outlet were conducted during flood and ebb on May 9, 2004.

To measure surface temperature in a Lagrangian view, a Seamon mini thermometer was attached to a drogue which is positioned by a Garmin Survey II GPS (Global Positioning System). The thermo-drogue, with a drag vane at a depth of $4 \mathrm{~m}$, was released at the outlet mouth at different tidal stages and recorded temperatures at depth $1 \mathrm{~m}$ along with its drifting trajectory. All measurements were conducted routinely during 20032004. Table 1 lists the durations and dates of observations.

\section{RESULTS AND DISCUSSION}

\section{Tides and currents}

This section analyzes the hourly sea level fluctuations at HPH in 2003. The mean tidal range is $1.102 \mathrm{~m}$; mean tidal ranges at spring and neap tides are $1.276 \mathrm{~m}$ and $0.646 \mathrm{~m}$, respectively. Table 2 lists harmonic constants (amplitudes and phases) for six principal tidal constituents $\left(O_{1}, P_{1}, K_{1}, N_{2}, M_{2}\right.$ and $\left.S_{2}\right)$. The tidal phase is referred to at GMT (Greenwich Mean Time). Amplitudes of dominant semidiurnal $M_{2}$ tide and diurnal $K_{1}$ tide are comparable. The form ratio, defined as an amplitude ratio $\left(O_{1}+K_{1}\right) /\left(M_{2}+S_{2}\right)$, is 1.107 , indicating comparable contributions from diurnal and semidiurnal 
Table 1. Durations and dates of the hydrographic observations during 2003-2004

\begin{tabular}{cccc}
\hline Observation no. & Current & CTD & Drogue tracking \\
\hline 1 & $2003 / 1 / 17-2003 / 3 / 2$ & $2003 / 3 / 1$ & $2003 / 3 / 2$ \\
2 & $2003 / 4 / 13-2003 / 5 / 8$ & $2003 / 5 / 7$ & $2003 / 5 / 6$ \\
3 & $2003 / 8 / 1-2003 / 8 / 17$ & $2003 / 8 / 1$ & $2003 / 8 / 2$ \\
4 & $2003 / 10 / 22-2003 / 12 / 11$ & $2003 / 11 / 1$ & $2003 / 12 / 11$ \\
5 & $2004 / 2 / 17-2004 / 3 / 24$ & $2004 / 2 / 17$ & $2004 / 2 / 18$ \\
6 & $2004 / 5 / 6-2004 / 6 / 5$ & $2004 / 5 / 7$ & $2004 / 5 / 6$ \\
\hline
\end{tabular}

* intensive CTD survey

Table 2. Principal tidal harmonic constants for tidal sea levels at HPH. The time base is GMT

\begin{tabular}{cccc}
\hline Constituents & Frequency $(\mathrm{cph})$ & Amplitude $(\mathrm{m})$ & Phase $\left(^{\circ}\right)$ \\
\hline$O_{1}$ & 0.038731 & 0.198 & 111.6 \\
$P_{1}$ & 0.041553 & 0.070 & 134.0 \\
$K_{1}$ & 0.041781 & 0.216 & 138.6 \\
$N_{2}$ & 0.078999 & 0.054 & 311.4 \\
$M_{2}$ & 0.080511 & 0.260 & 316.8 \\
$S_{2}$ & 0.083333 & 0.115 & 331.7 \\
\hline
\end{tabular}

constituents. This tidal character is attributed to the dominance of the westward-propagating Pacific tidal waves in the bay. The diurnal components propagating through the Luzon Strait into the South China Sea are markedly amplified (Yanagi and Takao, 1998; Jan et al., 2002), and may additionally modulate tidal behavior in the bay.

Currents over the inner reach adjacent to the power plant are predominantly driven by tidal forcing and the major current direction is essentially parallel to the local coast line. Fig. 2 illustrates the stick diagrams of currents acquired in the sixth measurement, the low pass filtered subtidal currents, and local winds at $\mathrm{HC}$. The cutoff frequency of the low pass filter is 0.0278 cycles/hr (equivalent to a period of $36 \mathrm{hrs}$ ), removing most of the tidal signal. Currents during various measurement periods have similar statistical properties to those presented in Fig. 2, suggesting that the current fluctuation is probably unrelated to seasonal variation. Therefore, this study presents only results derived from the sixth measurement. Current direction statistics indicate that about $65 \%$ of currents flow in directions within SSW to WSW. The mean flow is steadily southwestward-flowing $\left(225^{\circ}-235^{\circ}\right)$ with a velocity ranging from $0.15-0.18 \mathrm{~m} / \mathrm{s}$ during each observation. No appreciable correlation was found between the subtidal currents and local winds. Results presented in Liang et al. (1978) indicate that the spatial and temporal variations of mean currents in the bay are complicated. Mean current at their station $\mathrm{C}$ which is about $2 \mathrm{~km}$ east of our current meter station CUR constantly flows toward west. This eastward-flowing mean current mainly contributes to the southwestward mean current at CUR. The variation of subtidal currents may be caused by remote forcing such as fluctuations of the northern South China Sea circulation, the Kuroshio and the internal tides (Lien et al., 2004) and warrants further investigations including long-term monitoring of currents, winds and sea levels in the bay and vicinity.

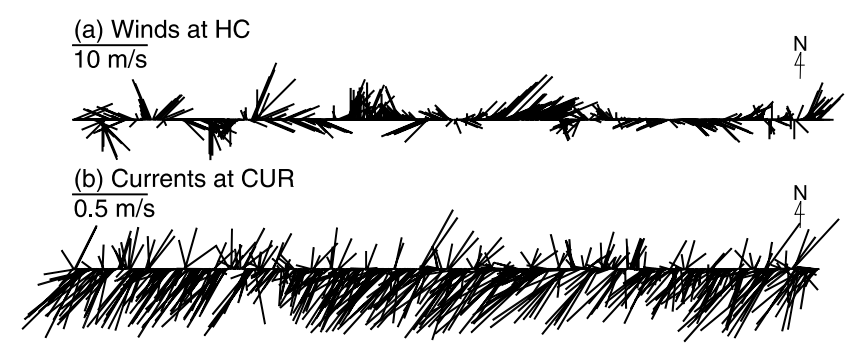

(c) Subtidal currents at CUR

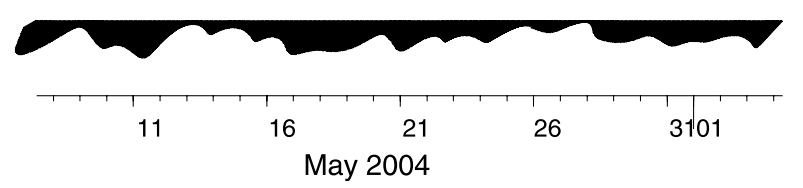

Fig. 2. Stick diagram for (a) winds at the weather station HC, (b) currents at current meter station CUR, and (c) low pass filtered (cutoff frequency $=\mathbf{0 . 0 2 7 8} \mathrm{cycles} / \mathrm{hr}$ ) subtidal currents at CUR. 
Table 3. Major harmonic constants for measured tidal currents (2004/5/7/9:00-2004/6/4/8:00) at CUR. The phase is referred to GMT

\begin{tabular}{cccccc}
\hline Constituents & Frequency (cycles/hr) & Semi-major $(\mathrm{m} / \mathrm{s})$ & Semi-minor $(\mathrm{m} / \mathrm{s})$ & Orientation $(\mathrm{deg})$ & Phase $(\mathrm{deg})$ \\
\hline$O_{1}$ & 0.038731 & 0.0775 & -0.0225 & 59.4 & 123.8 \\
$K_{1}$ & 0.041781 & 0.1116 & -0.0210 & 53.3 & 156.9 \\
$M_{2}$ & 0.080511 & 0.1523 & -0.0075 & 57.3 & 68.6 \\
$S_{2}$ & 0.083333 & 0.0402 & -0.0197 & 58.8 & 114.3 \\
$M K_{3}$ & 0.122292 & 0.0551 & 0.0129 & 52.7 & 205.5 \\
$M_{4}$ & 0.161023 & 0.0471 & 0.0176 & 43.4 & 79.3 \\
$M S_{4}$ & 0.163845 & 0.0482 & 0.0029 & 52.8 & 106.5 \\
\hline
\end{tabular}

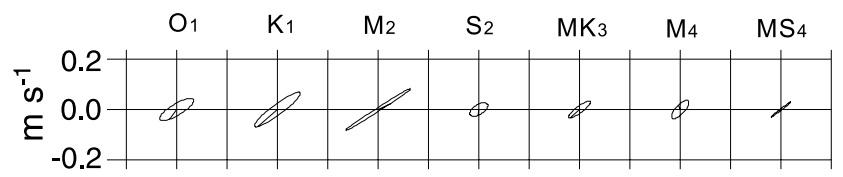

Fig. 3. Tidal current ellipses for seven major tidal constituents, $O_{1}, K_{1}$, $M_{2}, S_{2}, M K_{3}, M_{4}$ and $M S_{4}$.

Table 3 summarizes the major harmonic constants for tidal currents at CUR. The semidiurnal $M_{2}$ and diurnal $K_{1}$ tides, with comparable semi-major axes of 0.1523 and $0.1116 \mathrm{~m} / \mathrm{s}$ respectively, are the largest two tidal current components. Compound tides $\left(M K_{3}\right.$ and $\left.M S_{4}\right)$ and overtides $\left(M_{4}\right)$ also contribute significantly to overall tidal currents. These high frequency components appear to be produced by non-linear interaction of semidiurnal and diurnal tides over shallow water regions. Fig. 3 shows associated tidal current ellipses for the seven constituents, confirming that the major tidal current axis is aligned closely with the coast line.

Current velocities are decomposed to cross-shore (u) and long-shore (v) components for further analysis. The conventional current spectrum generated by the Fourier analysis (not shown) provides dominant peaks at diurnal and semidiurnal frequencies and minor peaks at various other frequencies. However, temporal variation information is lost and individual variations cannot be identified. The Morlet wavelet transform circumvents this deficiency. Fig. 4 shows the time series of sea level, cross- and long-shore velocity components and their wavelet transforms, and temperature and its wavelet transform. The cross-shore velocities are relatively small, mostly fluctuating within $\pm 0.1 \mathrm{~m} / \mathrm{s}$. By comparison, the long-shore component fluctuates vigorously; its velocity can reach $-0.6 \mathrm{~m} / \mathrm{s}$. The disparity of tidal currents during flood and ebb is clear in the long-shore component and is attributed to the current-topography interaction produced cyclonic eddy, especially during ebb, in the bay (Lee et al., 1999a). The wavelet transform coefficients for cross-shore and long-shore components are shown as gray images in the lower panels of (a)

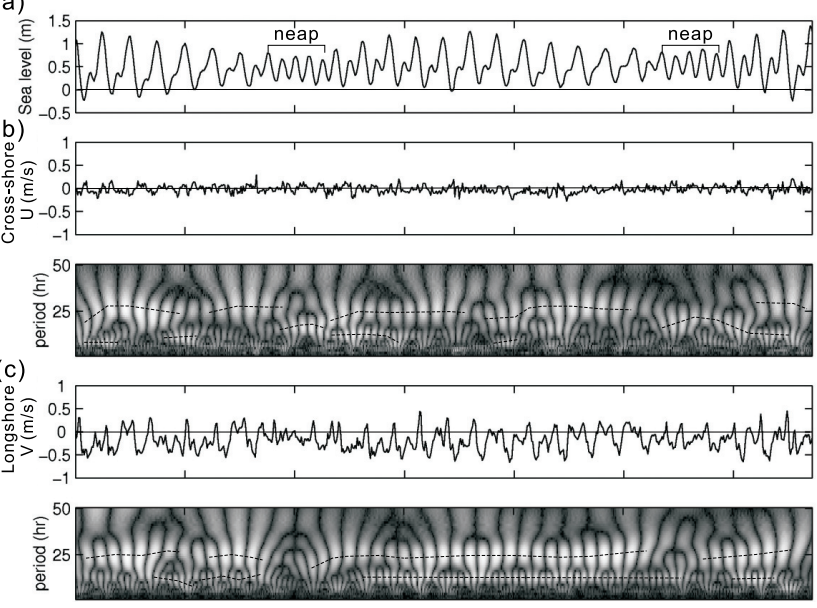

(d)

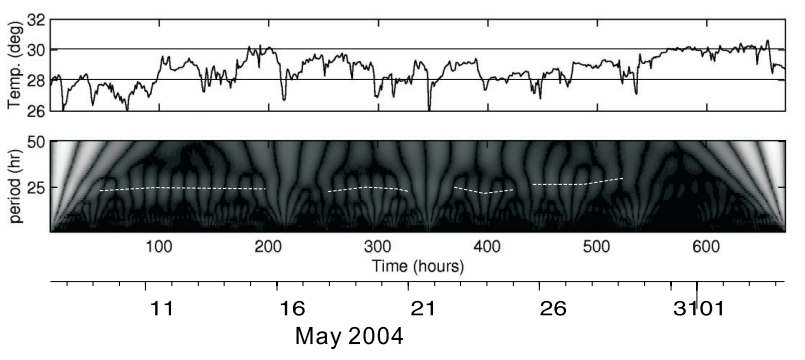

Fig. 4. Time series of (a) sea levels at the tide-gauge station HPH, (b) cross-shore velocity component at CUR and its wavelet transform coefficients, (c) long-shore velocity component and its wavelet transform coefficients, and (d) temperature and its wavelet transform coefficients. The gray colors in low panels of $(b)$ - (c) represent the relative magnitude of the wavelet coefficient. The brighter the gray scale is, the higher the energy. The dashed lines indicate peak wavelet transform coefficients as time progresses.

Figs. 4 (b) and (c), respectively. The coefficient indicates the correlation of the wavelet with this section of the signal (Emery and Thomson, 1998). A higher coefficient (as indicated by a brighter area in the image) implies a greater similarity. Figs 4 (b) and (c) demonstrate that the peak energy is distinct for diurnal and semidiurnal periods during spring tide and becomes blurred for diurnal periods during neap tide. The im- 
ages can also identify the peak energy changes during other periods, e.g. subtidal fluctuations, compound tides and overtides. Fig. 4(c) suggests that the high frequency fluctuation generally becomes clearer about two hours before the low slack water. Conceivably, the mixed tidal feature and the non-linear interaction with bottom topography cause the complicated behavior of tidal currents.

In tidal current analysis, the correlation between sea levels and tidal currents can be empirically estimated. Tidal currents can be captured by subtracting subtidal currents from the raw data. The squared coherency between long-shore tidal currents and sea levels is 0.94 and 0.89 at the diurnal and semidiurnal frequencies, respectively, which is above the $95 \%$ confidence limit of 0.77 . The corresponding phase is $-162^{\circ}$ and $-65^{\circ}$ for the two groups of tidal components, meaning that currents lag sea levels by $1.2 \mathrm{hrs}$ at diurnal frequencies and $3.8 \mathrm{hrs}$ at semidiurnal frequencies. Using a linear regression, hourly long-shore tidal currents can be expressed as functions of sea level fluctuations which are

$$
v_{1}(t)=0.1830 \times \eta(t-1)-0.0933
$$

at diurnal frequencies and

$$
v_{2}(t)=0.1858 \times \eta(t-4)-0.0938
$$

at semidiurnal frequencies ( $\eta$ : sea level in meters; $t$ : time in hours). The correlation coefficients for the two equations are 0.71 and 0.51 . The truncation of time lag to an integer in hours partially causes the reduction of correlation coefficients. By adding $v_{1}, v_{2}$ and the mean velocity $(-0.15 \mathrm{~m} / \mathrm{s})$ together, one can roughly estimate the long-shore currents by the empirical function

$$
v(t)=0.1830 \times \eta(t-1)+0.1858 \times \eta(t-4)-0.3371
$$

The root-mean-squared error of the estimation is 0.18 $\mathrm{m} / \mathrm{s}$. This estimation simply measures the current speed and direction outside the outlet to evaluate the fluctuation of the thermal plume, which will be discussed later. Possible reasons for the estimation-observation discrepancy include the use of ensemble mean velocity rather than varied subtidal flow in equation (1), the neglect of high-frequency compound tides and overtides, and the variability of dominant tidal currents in a springneap cycle [see Fig. 4(c)]. The current can be more accurately predicted by either using harmonic constants listed in Table 3 to compose tidal currents or using carefully calibrated numerical models to simulate the basin wide currents (Jiang et al., 2003; Lee et al., 1999b).

\section{Temperature variations}

The sudden temperature drop is a prominent feature of the bay, receiving extensive studies in recent decades (e.g. Liang et al., 1978; Su et al., 1984; Lee et al., 1997 and 1999a). Lee et al. (1997) linked it to the tidally induced upwelling which occurs daily and preferably during spring tides. According to their results, the cold water intrusion usually begins after lower low tide and peaks before lower high tide. The temperature subsequently rises more slowly. This study investigates the reach of upwelled cold water close to the outlet. Fig. 4(d) shows temperature fluctuation at depth $6 \mathrm{~m}$ of the station CUR and the corresponding wavelet transform. Since the thermal effluents are generally buoyant in waters deeper than $3 \mathrm{~m}$, it does not appear to overwhelm the subsurface temperature fluctuation. Fig. 4(d) also clearly indicates sudden temperature drops on the time series of temperature. This suggests that the upwelled cold water can reach inside the embayment as close as $200 \mathrm{~m}$ southwest of the outlet. The amplitude of drops averages about $2^{\circ} \mathrm{C}$ and is occasionally greater than $3^{\circ} \mathrm{C}$. The duration of the cold anomaly ranges from 3 to 24 hrs. All six periods of measurements show the phenomenon, indicating a weak seasonal variation. The wavelet transform in Fig. 4(d) indicates that the temperature varies mainly at diurnal frequencies but the variation is not as apparent as that of tidal currents. The temperature drops and sea levels do not appear to have such a consistent relationship as that revealed by Lee $e t$ al. (1997). Comparing Fig. 4(d) with Fig. 4(a) reveals that the temperature may significantly drop and rise during spring (5/15) and neap (5/21) tides and may begin at different tidal level stages. Internal wave packets of the elevation type generally lasts only a few minutes each (Hsu et al., 2000), and may therefore be ruled out as the cause of temperature drops in Fig. 4(d). In any case, the richness of many types of temperature drops cannot be easily explained. The major cold anomaly in the inner reach near the outlet merits a thorough study.

Figure 5 shows horizontal temperature distributions at depths $1 \mathrm{~m}$ and $30 \mathrm{~m}$ at different tidal stages in a larger area. Fig. 5(a) reveals that during flood, the majority of the thermal effluents $\left(>26^{\circ} \mathrm{C}\right)$ are confined in the left side of the outlet hugging the east coast of the Mou-Bi-Tou, and do not reach the region off the inlet. A cold water zone $\left(<23.5^{\circ} \mathrm{C}\right)$ is located in the surface layer southeast of the outlet. In the central bay, the temperature remains at $24^{\circ} \mathrm{C}$ and varies little. Fig. 5(b) shows a colder zone $\left(<23^{\circ} \mathrm{C}\right)$ at depth $30 \mathrm{~m}$. The cold surface water could conceivably come from the up- 
welled cold bottom water. Of interest is that nutrients were also measured on the same day that temperatures were taken on February 17, 2004 (Fig. 5). Fig. 6(a) shows distributions of nitrate at surface $(0 \mathrm{~m})$ and $10 \mathrm{~m}$ depth, respectively. Also shown on Fig. 6(b) are distributions of silicate at surface and $10 \mathrm{~m}$ depth (Unfortunately, there are insufficient nutrient data to plot contours at $30 \mathrm{~m}$ ). These figures all show higher nutrient concentrations near the cold water mass (Fig. 5). Therefore, upwelled subsurface waters are both cold and nutrient rich. More on upwelling is given in Chen $e t$ al. (this issue). Fig. 7 indicates that temperature distributions during ebb are different from those during flood (Fig. 5). Fig. 7(a) shows that thermal effluents $\left(>28^{\circ} \mathrm{C}\right)$ disperse as a fan shape around the outlet. A cold water zone $\left(<27.3^{\circ} \mathrm{C}\right)$ still exists southeast of the Mou-BiTou. Away from the shallow inner shelf, there is no appreciable temperature distribution pattern at the surface layer. At a depth of $30 \mathrm{~m}$, the cold water zone shifts eastward during the ebb [Fig. 7(b)]. The nearly isolated cold water zone can normally be observed extending
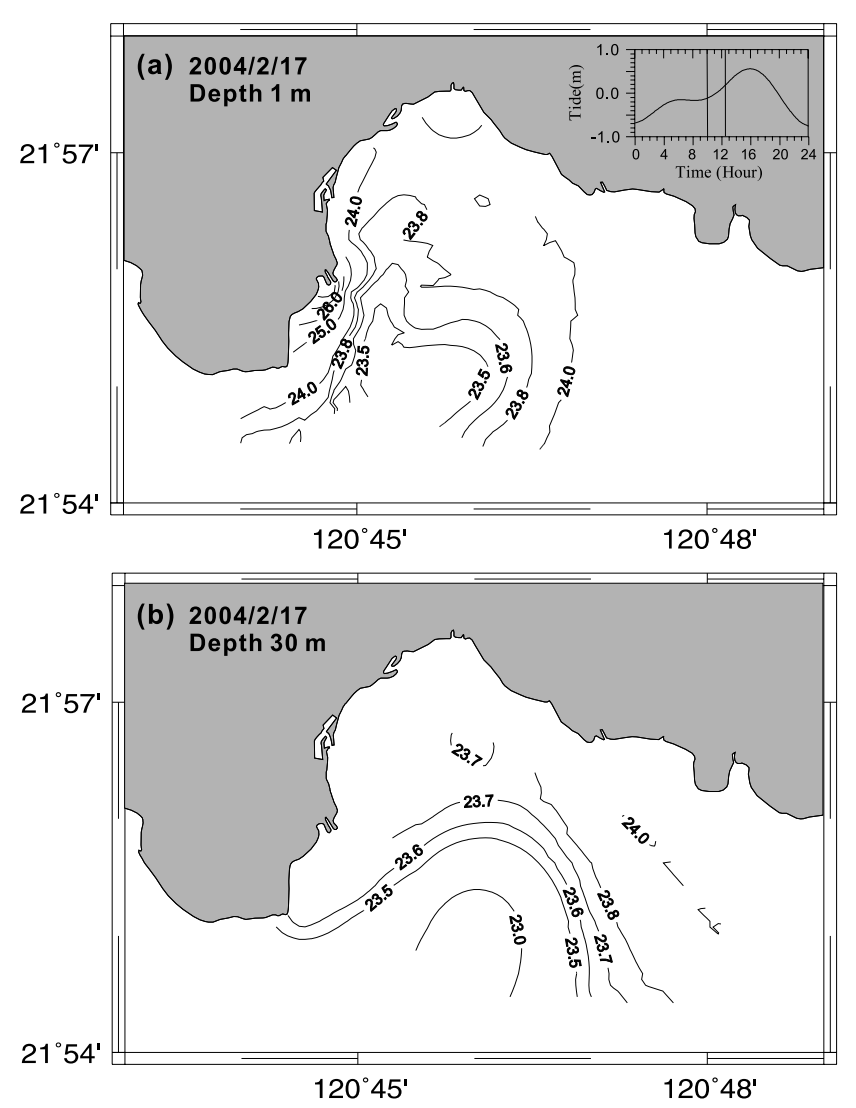

Fig. 5. Larger domain temperature distributions at depths (a) $1 \mathrm{~m}$ and (b) $30 \mathrm{~m}$ observed during flood (2004/2/17/10:04-12:35). The small inset in the upper-right corner of (a) indicates sea levels at HPH; the two vertical lines represent start and end times of the CTD survey. Contours are in ${ }^{\circ} \mathrm{C}$. from deep to surface layers despite the tidal phase variation. Regardless of the complexity of the sudden temperature drop, tidally-induced upwelling probably causes the cold anomaly (Lee et al., 1999b).

Figure 8 shows drogue trajectories and associated temperature variations at $1 \mathrm{~m}$ below sea surface. During flood, drogue trajectories are similar for all measurements and can be represented by Fig. 8(a). The drogue drifts southward around the Mou-Bi-Tou coast and tends to leave the bay, indicating that the warmer water parcel from the outlet is carried out of the bay during flood. The temperature drops rapidly from $32^{\circ} \mathrm{C}$ to $27^{\circ} \mathrm{C}$ in the first $300 \mathrm{~m}$ of the track, decreases slowly to $24^{\circ} \mathrm{C}$ in the subsequent $600 \mathrm{~m}$ drift, and remains at around $24^{\circ} \mathrm{C}$ thereafter [see lower panel of Fig. 8(a)]. The tidal excursion is estimated at $6 \mathrm{~km}$ in a flood period. During ebb, all drogue trajectories exhibit the same eastwarddrifting tendency near the outlet, but become somewhat diverse farther away. Fig. 8(b) shows only one ebb trajectory, which moves eastward from 9:30 to 11:30 and thereafter deflects cyclonically towards the outlet. Since the drogue was released southwest of the outlet, the temperature rises initially, peaks at $32^{\circ} \mathrm{C}$ at the outlet mouth and falls after passing the mouth. At around $300 \mathrm{~m}$ from the outlet, the temperature decreases to $28^{\circ} \mathrm{C}$ with little fluctuation. The tidal excursion during an ebb period is approximately $3 \mathrm{~km}$. The floodebb current disparity conceivably leads to the discrepancy of tidal excursion between the two tidal phases. The information generated from the thermo-drogue observations indicates that the thermal discharge parcel
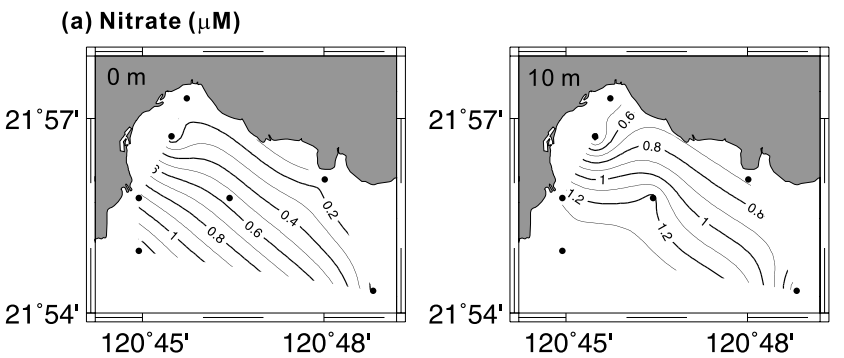

(b) Silicate $(\mu \mathrm{M})$
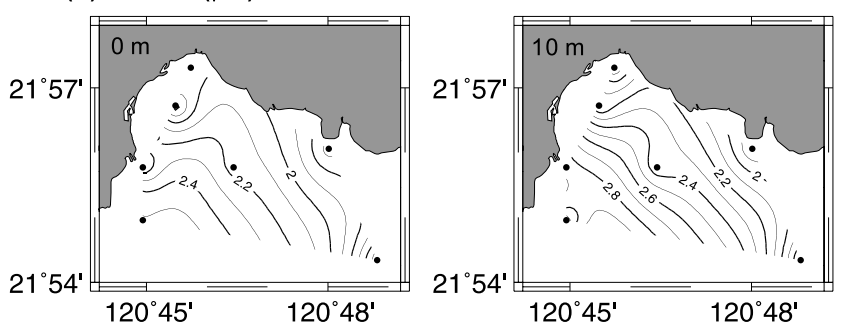

Fig. 6. Distributions of (a) nitrate and (b) silicate at depths $0 \mathrm{~m}$ (surface) and $10 \mathrm{~m}$. The samples were taken on February 17, 2004. Dots represent sample stations. 

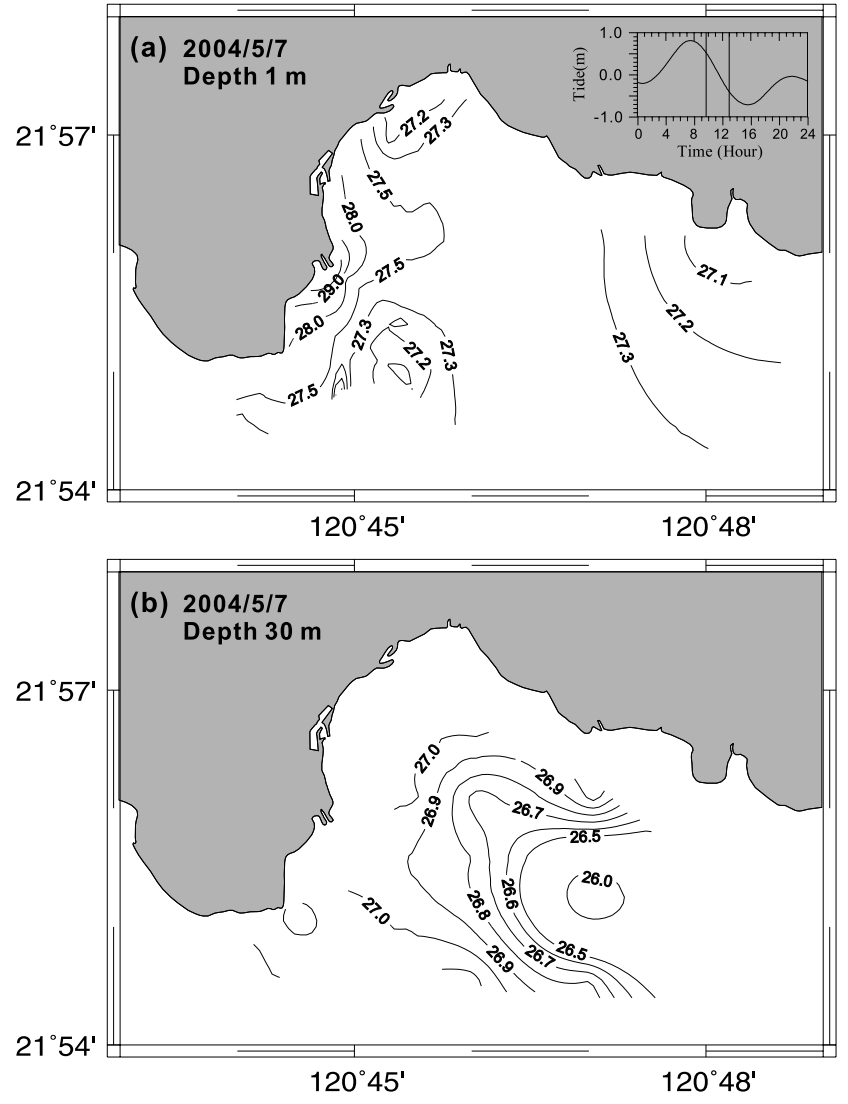

Fig. 7. Same as Fig. 5 but observed during ebb (2004/5/7/8:45-12:56). has a spatial temperature drop rate of about -0.008 to $-0.01^{\circ} \mathrm{C} / \mathrm{m}$ within a distance of $500-800 \mathrm{~m}$ measured from the outlet.

Results of larger domain CTD surveys in Figs. 5 and 7 show essential temperature distribution features in the western bay. However, the spatial resolution is too coarse to examine the fine structure of thermal effluents. The intensive CTD surveys within $1,000 \mathrm{~m}$ radius of the outlet on May 9, 2004 were conducted to better resolve temperature distribution. To illustrate the temperature structure, Fig. 8 shows perspective views of temperature variations at depth $1 \mathrm{~m}$ during successive flood and ebb tides. After the thermal wastewater discharges into the sea, its temperature drops rapidly within a $500 \mathrm{~m}$ radius around the outlet and approaches the background temperature outside a 1,000 $\mathrm{m}$ radius around the outlet. The radial temperature gradient is estimated as $-0.01^{\circ} \mathrm{C} / \mathrm{m}$ within the $500 \mathrm{~m}$ radius, which corresponds to the results calculated from thermo-drogue trajectory observations. The shape of thermal plume is tongue-like extending about $600 \mathrm{~m}$ from the outlet southward during flood, but fans out around the outlet during ebb (see lower panels of Fig. 9). The tidal currents determine the variation of the plume shape. Fig. 10 shows the vertical temperature distribution in a radial transect across the thermal plume. The layer thickness of thermal effluents is 5-7 $\mathrm{m}$ right after discharge and becomes thinner $(<1 \mathrm{~m})$ as it propagates

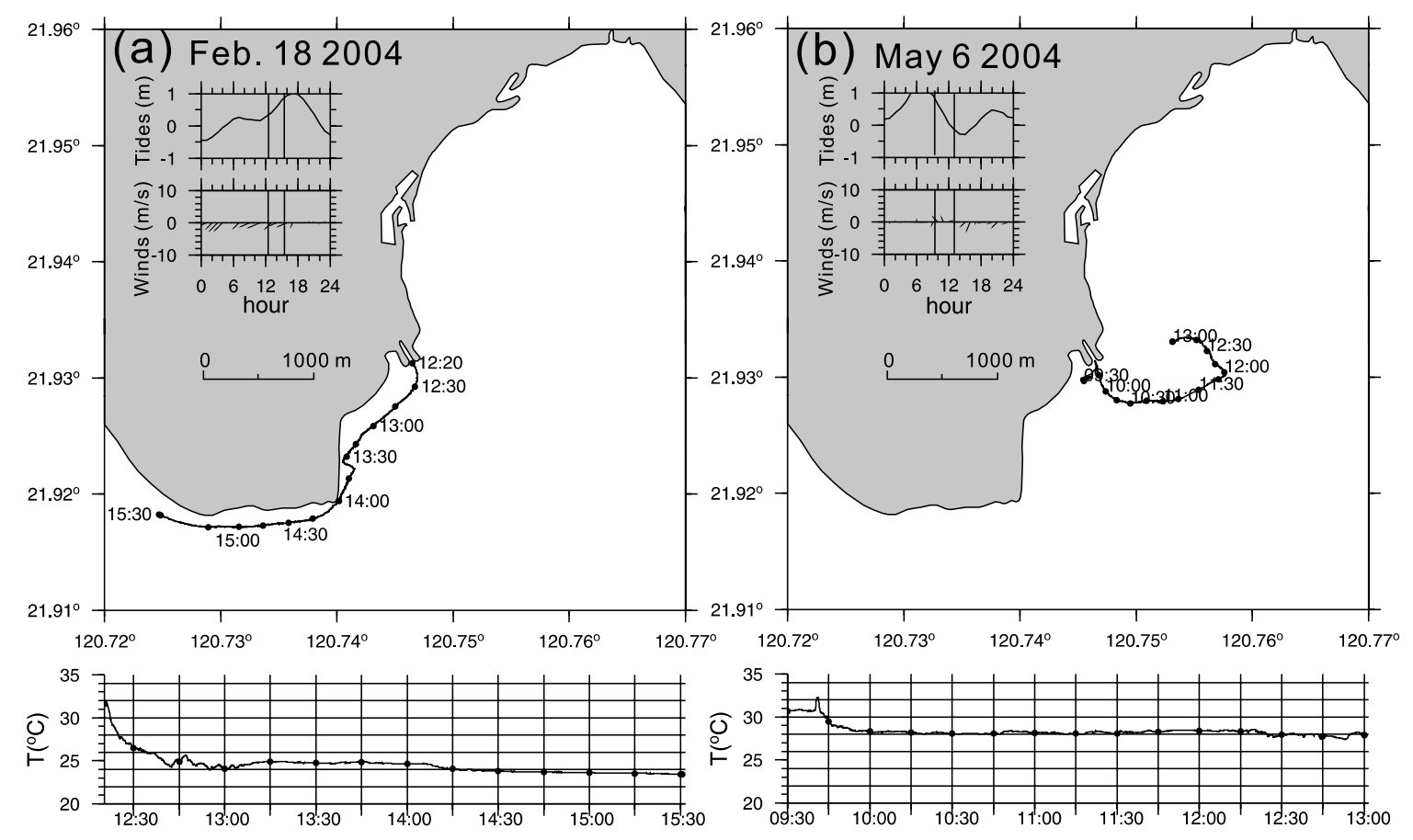

Fig. 8. Drogue trajectories and associated temperature variations at depth $1 \mathrm{~m}$. The drogue was released at the outlet mouth about (a) one hour after higher low water and (b) two hours after higher high water. Small insets indicate tides at HPH and winds at HC during the two dates. 


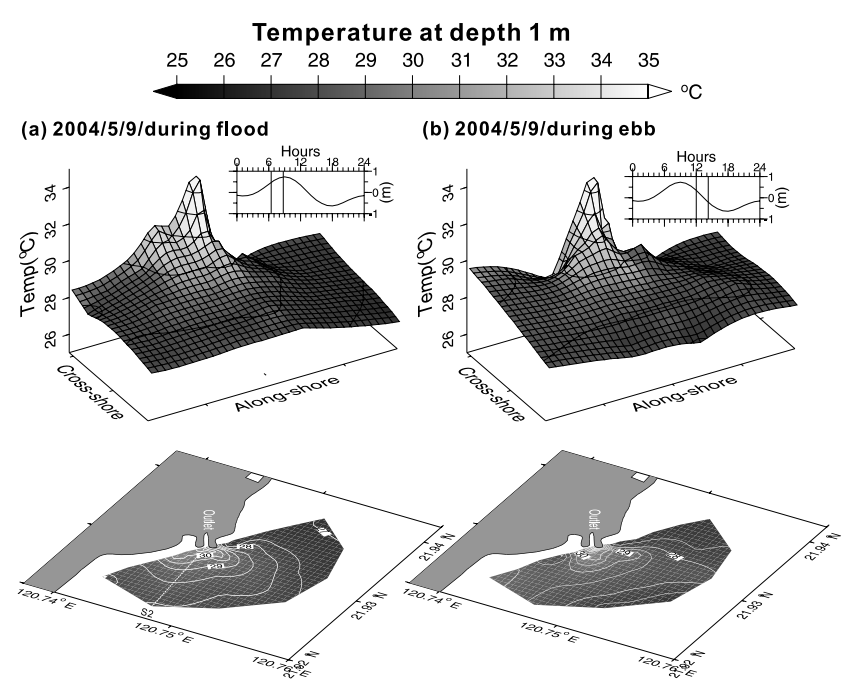

Fig. 9. Perspective views of spatial temperature variations measured during (a) flood and (b) ebb on May 9, 2004. The relative distances are 1,000 and $2,000 \mathrm{~m}$, respectively, on the crossshore and long-shore sides. The white dashed line in lower panel of (a) represents a temperature transect. The insets indicate sea level fluctuations in which two vertical lines mark start and end times of each survey.

seaward. The temperature distribution in Fig. 10 captures the typical vertical structure of the released thermal discharge.

\section{CONCLUDING REMARKS}

Sea level, current, temperature and drifter trajectory measurements were systematically conducted during 2003-2004 to better resolve spatial and temporal variations of the hydrography in the coastal sea close to the third nuclear power plant of Taipower. The dominant tides are a mixture of diurnal and semidiurnal tides, with the former slightly larger than the latter. Results derived from current measurements suggest that the nearshore currents are dominated by tidal forcing, flowing southwestward during flood and northeastward during ebb. The amplitudes of tidal currents range from 0.2 to $0.4 \mathrm{~m} / \mathrm{s}$. The compound tides and overtides produced high frequency fluctuations occupy a sizable fraction of tidal currents in the shallow shelf of the embayment. The southwestward-flowing subtidal current is relatively weak (approximately $0.15 \mathrm{~m} / \mathrm{s}$ ) and is probably independent of seasonal variation. The longshore currents can be estimated simply by using real time sea level observations $[\eta(t)]$ through the equation:

$$
v(t)=0.1830 \times \eta(t-1)+0.1858 \times \eta(t-4)-0.3371
$$

The root-mean-squared error of the estimation is 0.18

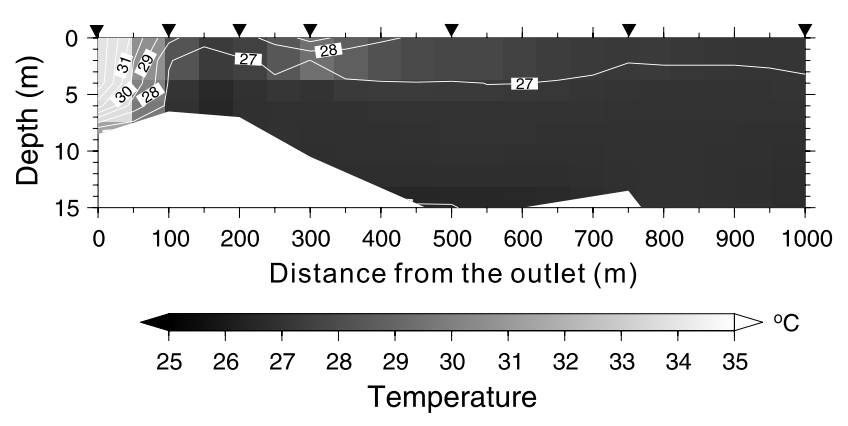

Fig. 10. Temperature distribution in a radial transect (S2 transect in Fig 8). The inverted triangles indicate location of CTD casts.

$\mathrm{m} / \mathrm{s}$.

The sudden temperature drops are observed as close as $200 \mathrm{~m}$ from the outlet. Discharge of heated cooling water from the power plant produces a buoyant thermal plume, forming the most striking hydrographic feature in the coastal ocean. The thermal plume occupies 5-7 $\mathrm{m}$ thick in the surface layer right after discharge, becomes thinner when it is dispersed farther seaward, and is essentially restricted within about $1,000 \mathrm{~m}$ from the outlet. The horizontal plume shape, stretching $600 \mathrm{~m}$ southwestward along the coast during flood and becoming a small bulge-like shape expanding towards northeast during ebb, is mostly dictated by the coastal currents. The thermal discharge does not recirculate back to the inlet. The intensive CTD surveys and drogue trajectory observations both show that the thermal effluents have a spatial temperature drop rate of about -0.008 to $-0.01^{\circ} \mathrm{C} / \mathrm{m}$ at $500-800 \mathrm{~m}$ away from the outlet.

This work uses intensive observations to describe spatial and temporal variations of currents and hydrography in the coastal ocean adjacent to the nuclear power plant. Further work is required to develop a high-resolution three-dimensional numerical model to simulate the inner shelf circulation and the dispersion of the thermal effluents. The model would benefit from monitoring of the thermal plume using towed CTD and ADCP (Acoustic Doppler Current Profiler).

\section{ACKNOWLEDGEMENTS}

The Taiwan Power Company funded the project. Ms. B.-J. Wang kindly provided nutrient data. Mr. J.-T. Wen and Mr. F.-H. Huang assisted field work. Comments from two anonymous reviewers and invaluable suggestions from Prof. Shenn-Yu Chao of the University of Maryland Center for Environment Science (UMCES) improved the presentation of the paper. 


\section{REFERENCES}

1. Chen, C.T.A., Ou, S.-C., Chung, Y.-C., Wu, C.-K., and Chun, L.-R., Research of Living Resources Around the Nuclear Power Plant in Southern Taiwan, Tech. Rep. 20, College of Marine Sciences, National Sun Yat-Sen University, Kaohsiung, Taiwan (1994). (in Chinese)

2. Chen, C.T.A., Jan, S., Chen, M.-S., Liu, L.-L., Huang, R.-F., Chun, L.-R., Chung, Y.-C., and Chun, L.-R., Investigation of Ecosystem in Seas Around the Third Nuclear Power Plant and Lanyu, Investigation Report of the Taiwan Power Company (2003). (in Chinese)

3. Emery, W.J. and Thomson, R.E., Data Analysis Methods in Physical Oceanography, Pergamon, Elmsford, New York (1998).

4. Fan, K.-L., "The Thermal Effluent Incident of the Third Nuclear Power Plant in Southern Taiwan," Acta Oceanogr. Taiwanica, No. 20, pp. 117-125 (1988).

5. Foreman, M.G.G., "Manual for Tidal Heights Analysis and Prediction," Institute for Ocean Sciences, Sidney, Canada, Pacific Marine Science Report, No. 77-10 (1977).

6. Hsu, M.-K., Liu, A.-K., and Liu, C., "A Study of Internal Waves in the China Seas and Yellow Sea Using SAR," Cont. Shelf Res., No. 20, pp. 389-410 (2000).

7. Jan, S., Chern, C.-S., and Wang, J., "Transition of Tidal Waves from the East to South China Seas over the Taiwan Strait: Influence of the Abrupt Step in the Topography," J. Oceanogr., 58, pp. 837-850 (2002).

8. Jiang, J., Fissel, D. B., and Topham, D., "3D Numerical Modeling of Circulations Associated with a Submerged Buoyant Jet in a Shallow Coastal Environment," Estuar. Coast. Shelf Sci., No. 58, pp. 475-486 (2003).

9. Lee, H.-J., Chao, S.-Y., Fan, K.-L., Wang, Y.-H., and Liang, N.-K., "Tidally Induced Upwelling in a Semienclosed Basin: Nan Wan Bay," J. Oceanogr., No. 53, pp. 467-480 (1997).

10. Lee, H.-J., Chao, S.-Y., Fan, K.-L., and Liang, N.-K., "Flood-ebb Disparity of Tidally Induced Recirculation Eddies in a Semi-Enclosed Basin: Nan Wan Bay," Cont. Shelf Res., No. 19, pp. 871-890 (1999a).

11. Lee, H.-J., Chao, S.Y., Fan, K.L., and Kuo, T.Y., "Tideinduced Eddies and Upwelling in a Semi-Enclosed Basin: Nan Wan," Estuar., Coast. Shelf Sci., No. 49, pp. 775-787 (1999b).

12. Liang, N.-K., Lien, S.-L., Chen, W.-C., and Chang, H.-T., Oceanographic Investigation in the Vicinity of Ma-An-San and Nan Wan Bay, Special Publication No. 18, Inst. of Oceanography, National Taiwan Ocean Univ., Keelung, Taiwan (1978).

13. Lien, R.-C., Chen, C.T.A., Lee, I.-H., and Liang, W.-D., "Turbulence Mixing, Nonlinear Internal Waves and In- ternal Tides in Luzon Strait," Abstract of 2004 Taiwan's Ocean Science Conference, Lungtan, Taoyuan. p. 22 (2004).

14. Morlet, J., "Sampling Theory and Wave Propagation," Issue in Acoustic Signal/Image Processing and Recognition, Vol. 1, NATO ASI Series, Springer-Verlag, Berlin/New York, pp. 233-261 (1983).

15. Su, J.-C., Hung, T.-C., Chiang, Y.-M., Tan, T.-H., Chang, K.-H., Shao, K.-T., Hwang, P.-P., Lee, K.-T., Huang, C.-C., Huang, C.-Y., Fan, K.-L., and Yeh, S.-Y., An Ecological Survey on the Waters Adjacent to the Nuclear Power Plant in Southern Taiwan, Special publication No. 27, National Scientific Committee on Problems of the Environment, Academia Sinica, Taipei, Taiwan, ROC (1984). (in Chinese)

16. Su, J.-C., Hung, T.-C., Chiang, Y.-M., Tan, T.-H., Chang, K.-H., Shao, K.-T., Hwang, P.-P., Lee, K.-T., Huang, C.-C., Huang, C.-Y., Fan, K.-L., and Yeh, S.-Y., An Ecological Survey on the Waters Adjacent to the Nuclear Power Plant in Southern Taiwan, Special publication No. 70, National Scientific Committee on Problems of the Environment, Academia Sinica, Taipei, Taiwan, ROC (1989). (in Chinese)

17. Su, J.-C., Hung, T.-C., Chiang, Y.-M., Tan, T.-H., Chang, K.-H., Shao, K.-T., Hwang, P.-P., Huang, C.-C., Huang, C.-Y., Fan, K.-L., and Yeh, S.-Y., An Ecological Survey on the Waters Adjacent to the Nuclear Power Plant in Southern Taiwan, Special publication No. 84, National Scientific Committee on Problems of the Environment, Academia Sinica, Taipei, Taiwan, ROC (1991). (in Chinese)

18. Yanagi, T. and Takao, T., "A Numerical Simulation of Tides and Tidal Currents in the South China Sea," Acta Oceanographica Taiwanica, Vol. 37, No. 1, pp. 17-29 (1998).

19. Yu, J.-L., Liou, J.-Y., Jan, S., Kao, S.-J., Hwung, H.-H., and Kao, R.-C., Field Inspection and Investigation on Thermal Diffusion of Nuclear Power Plant (Since Oct. 1999 to Dec. 2001), Tainan Hydraulic Laboratory, National Cheng Kung University, Bulletin No. 245 (2001). (in Chinese)

20. Yu, J.-L., Liou, J.-Y., Jan, S., Kao, S.-J., Hwung, H.-H., and Kao, R.-C., Field Inspection and Investigation on Thermal Diffusion of Nuclear Power Plant (Since Sep. 1998 to Jul. 1999), Tainan Hydraulic Laboratory, National Cheng Kung University, Bulletin No. 228 (1999). (in Chinese)

21. Yu, J.-L., Liou, J.-Y., Jan, S., Kao, S.-J., Hwung, H.-H., and Kao, R.-C., Field Inspection and Investigation on Thermal Diffusion of Nuclear Power Plant (Since Sep. 1997 to Aug. 1998), Tainan Hydraulic Laboratory, National Cheng Kung University, Bulletin No. 219 (1998). (in Chinese) 